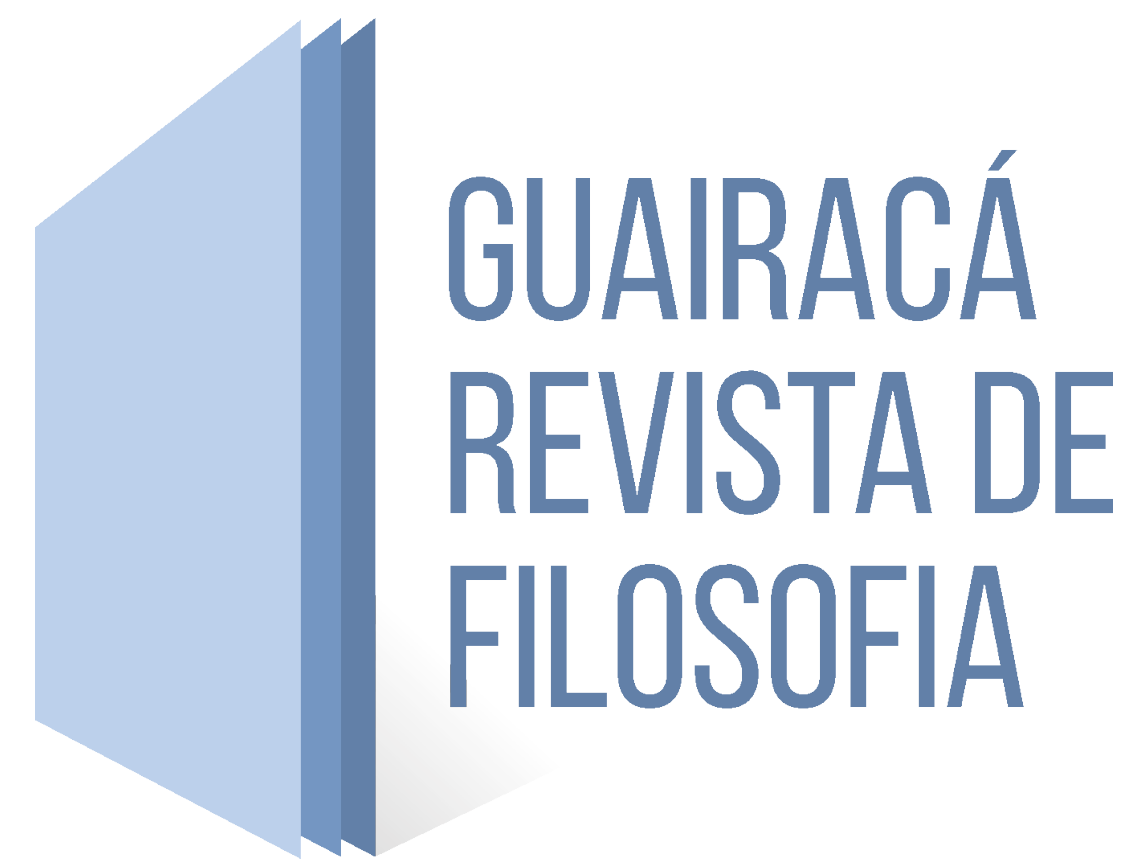

\title{
A INDÚSTRIA 4.0 E A FILOSOFIA: UM ENCONTRO TRANSDISCIPLINAR
}

Resumo: Vivemos em um tempo de transformações e de remodelagem tecnológica chamado de Indústria 4.0. Tempo que implica na transformação de vários espaços consolidados, alterando significativamente a maneira como vivemos e nos relacionamos nos ambientes em queestamos circunscritos. O trabalho, a comunicação, os modelos de negócios, o sistema de moradia e as relações interpessoais são apenas alguns dos espaços que já sofrem e que ainda sofrerão a ingerência desta mudança. $\mathrm{O}$ artigo fará uma análise documental a partir dos últimos textos publicados no site do WEF (https://www.weforum.org/), para verificar a hipótese que existem nos dispositivos de enunciação da Indústria 4.0 um deslocamento instrumental em vistas de uma lógica comportamental nos sujeitos no capitalismo hodierno. Para desenvolver este argumento o trabalho está dividido em três partes. Na primeira parte serão estruturadas as bases epistemológicas dadas em Klaus Schwab - um dos principais interlocutores do tema na WEF - na divulgação da ideia da Indústria 4.0; na sequência uma tentativa de diálogo entre conceitos de filosofia e da geografia para construir possibilidades de análise; na última parte serão propostas as consequências desta correlação pensadas sob a égide da ética como uma discussão inerente a filosofia da tecnologia. $\mathrm{O}$ artigo usa de conceitos transdisciplinares para pensar transformações paradigmáticas dadas pela ideia de uma nova revolução tecnológica que se anuncia.

Palavras-chaves: Desenvolvimento Regional. Filosofia. Indústria 4.0. World Economic Forum. Ética.

1. Universidade Regional de Blumenau. Email: albio.melchioretto@gmail.com 


\title{
4.0 INDUSTRY AND PHLLOSOPHY: A TRANSDISCIPLINARITY MEETING
}

\begin{abstract}
We live in a time of transformation and technological reshaping called the fourth industrial. Time that implies the transformation of various consolidated spaces, significantly altering the way we live and relate in the environments in which we are circumscribed. Work, communication, business models, housing and interpersonal relationships are just some of the spaces that already suffer and will still suffer the interference of this change. The article will make a documentary analysis from the last texts published in WEF website (https://www.weforum. org/), to verify the hypothesis that there are in the enunciation devices of the fourth industrial an instrumental displacement in view of a behavioral logic in the subjects in today's capitalism. To develop this argument the work is divided into three parts. In the first part will be structured the epistemological basis given in Klaus Schwab - one of the main interlocutors of the theme in WEF - in the dissemination of the idea of the fourth industrial; following an attempt to dialogue between concepts of philosophy and geography to build possibilities of analysis; In the last part we will propose the consequences of this correlation thought under the aegis of ethics as a discussion inherent in the philosophy of technology. The article uses transdisciplinary concepts to think about paradigmatic transformations given by the idea of a new technological revolution that is coming.
\end{abstract}

Keywords: Regional development. Philosophy. The fourth industrial. World Economic Forum. Ethic

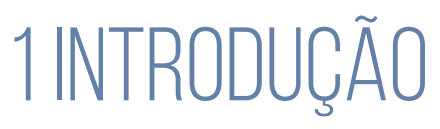

Em um tempo, não muito distante, era fácil encontrar pessoas que se orgulhavam do fato de passar a vida inteira de trabalho em única empresa, exercendo a mesma função, do início inexperiente, a "aprender uma profissão". Caminho encerrado na então sonhada "aposentadoria". Vivencia-se único itinerário profissional. Esta condição de trabalho, parece sofrer alterações significativas na história do tempo presente. Uma das discussões em torno das transformações é a apresentação da Indústria 4.0. Ao relacionar o mundo do trabalho com a revolução tecnológica, encontramos novas perspectivas e novos olhares sobre o trabalho, a relação humana com o trabalho, a inserção de novas tecnologias neste campo e por consequência, a mudanças de paradigmas trabalhistas. Estas modificações trazem 
novas características, uma pode ser a releitura no espaço que ocupamos, outra o desaparecimento de relatos de pessoas que dedicaram uma vida inteira a uma mesma "firma" ou a uma mesma função. São fatos que se tornam cada vez mais raros e estranhos.

As mudanças que são sugeridas pela Indústria 4.0, entre elas, as que se referem ao mundo do trabalho, são objeto deste artigo. Motivado por estas transformações, e pela tentativa de compreender esta nova estrutura que se apresenta, a partir de um viés tecnológico, justifica-se o presente artigo. Ele tem como proposta compreender um novo contexto que ainda não está normatizado. Um contexto, que de acordo com Schwab (2016), também não está limitado apenas ao modo como o humano relaciona-se com o trabalho, mas, estende-se a vivência geral. Embora, tenha o trabalho como ponto de partida. A nova onda tecnológica, mencionando um conceito de Case (2017), tende a causar transformações profundas e impactantes em nossas relações. Seja na perspectiva profissional ou pessoal. As transformações sugeridas, a partir destes teóricos, causarão um impacto na forma como pensamos e estudamos o desenvolvimento regional.

A reflexão é mediada através de uma pesquisa documental. Busca identificar como o tema Indústria 4.0 é tratado nas notícias do WEF. Nele, sustento a hipótese que exista um deslocamento puramente instrumental em vistas de uma lógica comportamental nos sujeitos no capitalismo hodierno. Entendemos e usamos no artigo, enunciação como uma produção de um enunciado. É o acontecimento constituído pelo surgimento de uma fala recorrente, que acrescenta um "jogo" de influências sociais, e por consequência, comportamentais. É a criação de uma estrutura discursiva, que desvela uma intencionalidade na fala. $\mathrm{O}$ que, Benvenieste (1978) categoriza como a constituição da subjetividade de um texto. Nas falas do WEF, encontramos uma produção de subjetividade ao enunciar a Indústria 4.0.

Por fim, apresentados os conceitos, supõe que esta transformação desemboque numa possibilidade em se repensar a questões a partir da ética. $O$ repensar ético traz um ponto de aproximação, com a ideia de uma ecologia sistêmica, a partir de Leonardo Boff (1993). Pensar a ética a partir deste contexto, dar-se-á por meio de uma consequência de ajuntamentos circunstanciais. Pensa-se uma nova forma de desenvolvimento, que transforma o espaço ocupado pelo ser humano. Em suma esta é discussão da Indústria 4.0. Para verificar e avaliar que esta mudança altera, o cenário que ele a Indústria 4.0 está inserida, é mister pensar e estabelecer critérios éticos. O que trará consigo também, uma mudança nos aspectos morais que determinam seu comportamento no dado espaço.

Alguns poderiam, até supor, que o campo de discussão, que aqui se apresenta, não é digno de preocupação. Para justificar, poder-se-ia afirmar, que a discussão sobre a Indústria 4.0 está limitada à estratégias políticas ou forças de 
poder que atravessa o campo político administrativo. Vide que hoje, organizações máximas de setores, como a Confederação Nacional da Indústria, CNI, se ocupam desta discussão. Outros ainda dirão que é uma questão político-econômica para geração (ou não) de empregos. Não são estas as questões propostas pelo artigo, embora caibam nestas proposições. Mas, ao analisar os dispositivos enunciativos da Indústria 4.0, desvela-se uma estrutura para além das questões políticas, refletindo, de modo sistêmico, como tais mudanças podem interferir na vida humana. Daí, que se propõe um olhar da ética sobre a vida, que sofre uma ação direta de um modelo em trânsito. Tomemos o exemplo que abre esta sessão. Se concordarmos que é difícil encontrar pessoas que se orgulham, ou que passem a carreira profissional inteira uníssona a única proposta, então, há de se considerar também, o aspecto ético de tal mudança, e não reduzir tudo ao plano político administrativo de território.

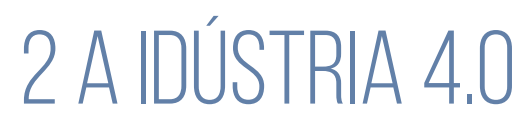

Esta seção tem por objetivo exibir o contexto onde a discussão do problema acontecerá. Para tal, se fazem necessárias, duas apresentações. A primeira delas, brevemente, a ideia de técnica, e a segunda, o que o artigo entende por Indústria 4.0, e sua correlação com a chamada Revolução 4.0. Os dois momentos se intercruzam porque se entende que a Indústria 4.0 é a apresentação de uma técnica com enunciação própria. A proposta desta seção, então, será construir o caminho que aproximam tais possibilidades.

A história contada a partir dos séculos XVIII e XIX do mundo ocidental, foi marcada por transformações de ordem da técnica, dada a partir da Revolução Industrial. Para pensar a questão da técnica, recorro a Heidegger (1977). Para o pensador alemão, a técnica, não é apenas um fazer humano, mas ela trata de um desabrigar, de um deixar de vir à tona. Ou ainda, um acontecimento ou aparecimento. A técnica é um modo de desvelar o ser e habitar no mundo. "Diz-se que a técnica moderna é algo totalmente incomparável com todas as outras técnicas anteriores, porque ela repousa sobre a moderna ciência exata da natureza" (HEIDEGGER, 1977, p. 381). O que faz apontar um possível movimento do desabrigar, ou ainda, do desvelar. Algo em curso que é desvelado a partir de uma essência, que repousa na armação. Como se algo fosse desabrigado a partir de uma ideia de utilização. O texto do Heidegger (1977) nos leva a pensar que exista uma espécie de governo técnico do mundo, e que diante da possibilidade, não há como evitar estes domínios. Como se o tempo que estamos fosse o espaço de desabrigar novas técnicas, que por ventura, possam transformar o modo como nos colocamos no mundo.

Se há um contexto de transformação no mundo, o mote inicial deste texto, que evidencia uma mudança comportamental no modo de produção, tem certo 
sentido dentro da reflexão. As transformações dadas e apresentadas pela técnica da Indústria 4.0, alargam seus braços para múltiplas direções. Para pensar esta perspectiva, a imagem de um novelo entrelaçado talvez possa ser adequada, embora possa parecer grotesca a analogia. Mas antes de discutir isto, apresento então, a segunda ideia que é o tema da Indústria 4.0.

A Revolução Industrial, é dividida, via de regra, por quatro fases. Segundo Schwab (2016), a primeira fase foi provocada pelo desenvolvimento da máquina à vapor, e como consequência, a produção mecânica em escala, substituindo a lógica de produção artesã-manufatureira. A segunda fase aconteceu entre o final do século XIX e início do Século XX, com o advento da eletricidade, possibilitando uma produção em massa. A terceira fase, deu-se no pós-guerra, impulsionada pelo contexto da Guerra Fria, com o advento da revolução digital e o desenvolvimento de semicondutores, que possibilitaram o surgimento da computação em mainframe. $\mathrm{O}$ fim da Guerra Fria, e o triunfo do capitalismo, segundo Bauman (2010), foi marcado, no campo do desenvolvimento tecnológico, pelo acesso comercial a internet. Este último acontecimento possibilitou o despertar da quarta fase da Revolução Industrial, chamada por muitos autores, como Schwab (2016), de Revolução 4.0 ou de Indústria 4.0. Embora exista uma diferença conceitual entre elas, este artigo, analisará ambas como sinônimos.

Apesar das últimas duas fases da Revolução Industrial pensarem o desenvolvimento dado a partir da tecnologia digital, há uma diferenciação considerável entre ambas. A quarta fase é marcada por uma transformação vivencial do uso da tecnologia digital. Ela não se limita apenas aos espaços de grandes corporações, de grandes capitalistas industriais, mas está dada ao alcance de todos e em todos os espaços, mas de maneira diferenciada. A inserção da tecnologia digital, transformou significativamente o modo de vida em escala universal. Se a primeira demorou, segundo Schwab (2016), aproximadamente 120 anos para se espalhar por toda a Europa, esta fase, em menos de uma década, é discutida em todo o planeta. As novas tecnologias, "estão causando rupturas à terceira Revolução Industrial; estão se tornando mais sofisticadas e integradas, consequentemente, transformando a economia global" (SCHWAB, 2016, p. 11). Com isso duas reflexões são possíveis. Primeiro, a análise que realizamos da Indústria 4.0 precisa ser feita com alguma cautela, porque, diferentemente das outras fases da Revolução Industrial, a leitura é dada de dentro dela. A análise acontece concomitante ao seu desenvolvimento. A segunda reflexão, está no fato que o modelo capitalista é adotado de forma homogênea, e de dentro dele que esta fase da Revolução Industrial se desenvolve, o que nos permite considerar que é uma análise que trasborda uma discussão puramente política. 
As primeiras discussões sobre a Indústria 4.0 aconteceram na Alemanha. Em Hannover Mess, no ano de 2011. Esta é uma feira industrial anual, realizada deste 1947. O que torna esta fase tão diferente das anteriores, além do aspecto vivencial da tecnologia, como já mencionado aqui, é "a fusão dessas tecnologias e a interação entre os domínios físicos, digitais e biológicos" (SCHWAB, 2011, p. 11). Este arranjo transdisciplinar, de acordo com Paul (2011), permite, lançar a hipótese que há um deslocamento da técnica como um fazer, um modo de produção para uma vivência. Não é meramente um meio, mas um desabrigar, a partir da leitura de Heidegger, que domina a técnica. Mas, o que este desabrigar significa?

Para responder esta questão, recorro a aquilo que está em discurso, num dos espaços de desvelamento da Indústria 4,0, que é o WEF. Uma das características apontadas nas discussões do WEF sobre a Indústria 4.0, é a maneira como o setor privado enxerga e se relaciona com o tempo. Na história do tempo presente, a questão vivencial do tempo é alterada de maneira significativa. Se num dado momento, uma pessoa qualquer, tinha como propósito aprender uma profissão, e, passar a vida inteira desenvolvendo-a numa mesma empresa, agora há outra realidade temporal. Segundo Brynjolfsson e McAfee (2019), as discussões apresentadas a partir do WEF, dão conta que, as pessoas que hoje estão na educação básica, trabalharão em profissões que ainda não existem e que trocarão de carreira, pelo menos quatro vezes ao longo de sua jornada profissional. Para Schwab (2016) a nova fase da Revolução Industrial e a ruptura com aquilo que está posto. Se um dos principais interlocutores deste discurso aponta a ruptura como uma consequência direcional, é interessante então repensar alguns conceitos., como trabalho, relação ser humano e máquina; a presença da tecnologia, entre outras características.

\section{UM NOVELO COM CORES DA FLLOSOFIA E COM CORES DA GEOGRAFIA}

Para desenvolver a pesquisa é importante evidenciar o uso da expressão dispositivo utilizado neste artigo. Ele é explicado a partir de Gilles Deleuze (1990), que utiliza as características aproximativas do rizoma para compreender, que um dispositivo, é uma espécie de novelo, um contíguo, em certo grau, multilinear. O conjunto é um composto de linhas de natureza diferente, e elas não abarcam, também nem delimitam sistemas homogêneos por sua própria conta. Estas duas características do dispositivo, permitem uma aproximação com tecnologias presentes na Indústria 4.0. Os dispositivos, para o pensador francês, têm várias dimensões, como linhas de visibilidade; enunciação; força; subjetivação; ruptura; 
fissura e fratura que se entrecruzam e misturam enquanto umas suscitam. Implicam em linhas de força que tanto se aproxima, quanto se afastam.

Para analisar a hipótese que há um deslocamento instrumental em vistas de uma lógica comportamental, que é a proposta do artigo, os recortes de divulgação, serão tomados como dispositivos de linha de enunciação. Estes enunciados tratam de um tempo atual com perspectiva de anúncio da história do tempo futuro. Diante do duplo jogo, entre a história do tempo presente, e a história do tempo futuro, encontramos, que "o atual não é o que somos, mas aquilo que vamos nos tornando, o que chegamos a ser, quer dizer, o outro, nossa diferente evolução" (DELEUZE, 1990, p. 159, tradução nossa). Um duplo jogo de pensar onde estamos, os devires envolvidos, e as possibilidades dadas a partir da enunciação para pensar a história do tempo futuro. O que torna tudo um grande novelo, de múltiplas linhas que são de natureza diferentes. Dito isto, apresentar-se-á os dados.

Para realização da pesquisa utilizou-se os textos encontrados no site do WEF que no campo de buscas, retornaram à pesquisa pela expressão, the Fourth Industrial. Foram delimitadas as chamadas datadas de 2019, ordenando-as cronologicamente através da busca avançada. Na ocasião foram selecionadas 51 chamadas. Destas foram escolhidas apenas 5 publicações para o artigo, por tratarem das questões pertinentes a ele. As publicações não selecionadas tratavam de questões díspares, ou eram as mesmas chamadas repetidas em língua espanhola ou francesa. A pesquisa aconteceu em 30 de março de 2019.

Das publicações visitadas, encontramos os seguintes apontamentos que se referem a uma perspectiva de paisagem.

1. Esses padrões compartilhados de pensamento e as histórias relacionadas, são ferramentas que criamos para fazer a sociedade funcionar como esperado e garantir o bem-estar dos indivíduos. Essas histórias são chamadas de narrativas intersubjetivas. Eles se tornam coordenados à realidade tangível em termos de valor de verdade (HEINOMEM; HYYTIÄLÄ, 2019, tradução nossa).

2. No início deste ano, a pesquisa Edelman Trust Barometer informou que apenas $20 \%$ das pessoas acreditam que os atuais sistemas econômicos e sociais trabalharam em prol de seus interesses. Na mesma linha, uma recente pesquisa do WEF sobre globalização revelou uma crença generalizada de que as iniciativas dirigidas pelo governo, como leis e regulamentos, não geram oportunidades suficientes. (LEVIN, 2019, tradução nossa).

3. Não devemos nos limitar a governar da maneira como governamos hoje, respondendo apenas de forma reativa às forças da mudança tecnológica. Em vez disso, precisamos governar proativamente de maneiras que nos tragam valores, tanto no privado quanto no público. Nós devemos governar pelo design. [...] Devido ao declínio da confiança nas instituições que tradicionalmente cuidavam da formulação de políticas, há um forte reconhecimento de que o desenvolvimento de políticas não está mais limitado aos governos ou as empresas (no caso de regulamentação do setor), mas sim a um esforço cada vez maior de participação múltipla (BASON. 
BROEKAERT, 2019, tradução nossa).

4. Necessita-se modelar uma arquitetura global (GAWEL, 2019, tradução nossa).

5. Aproveitar as oportunidades e gerenciar os desafios da Quarta Revolução Industrial exige uma sociedade civil próspera, profundamente envolvida com o desenvolvimento, uso e governança de tecnologias emergentes (WEF, 2019, tradução nossa).

Em Deleuze e Guattari (2013), fazer filosofia, em certo grau, é um processo artístico. É a criação de conceitos. É propor a criação de novelos. É buscar a essência para além da aparência que está posta, com a superação da visibilidade do óbvio. Neste caso, necessita-se também, desvelar a invisibilidade. Dos cinco enunciados, três deles, tecem uma crítica ao modelo político administrativo. Modelo consensual no mundo ocidental do pós-Guerra Fria. Os dados falam em superação do modelo sugerindo a ideia de um estado mínimo. Isso acontece nos números 2; 3 e 5 . Se tomarmos os números 1 e 4, encontramos uma ideia de transformação da paisagem. A paisagem o que está, não é possível permanecer. No fundo, os cinco enunciados tratam de mudança, mas com itinerários diferentes.

O contexto de conceituação da Indústria 4.0, no início de nossa década, tratava de questões tecnológicas. Falava-se das transformações envolvendo um ordenamento do fazer. Como por exemplo, os benefícios da Internet of Things (IoT) ou a Inteligência Artificial, ou ainda, da coleta de informações através de Big Data para pensar uma reestruturação do processo industrial produtivo. Porém, o que os enunciados aqui recortados dizem, é outra coisa. São falas voltadas para atitudes no campo da gestão dos espaços públicos. São feitos por novas formas de políticas, um tanto instrumentais, que valorizam a iniciativa privada e preveem estados menos burocratizados com fronteiras flexíveis. Garantam uma nova arquitetura global, como apontado no número 4 , o que caracteriza como uma análise dissociativa. Não é um dispositivo em favor de novas técnicas, mas é uma nova tecnologia de poder. Um novo processo, que deixa de lado uma preocupação ecoespacial, para determinar atitudes em torno da Revolução 4.0. É uma interpretação que vai além da face visível do espaço. Oblitera, em certo modo, a produtividade manual, para pensar um estado de gestão. É como se fosse uma nova fase da Indústria 4.0, mistificando uma necessidade de mudança. Classifica o fazer político do Pós-Guerra Fria, no mundo ocidental, como obsoleto diante do quadro de transformação que percebemos em todos os enunciados aqui descritos.

Para dar conta destes aspectos, se faz imprescindível, uma leitura transdisciplinar com a geografia. Uma criação de um novelo com fios de duas cores, uma da filosofia e outra da geografia. Recorro a Milton Santos para pensar a ideia de paisagem para compreender as transformações acima descritas. A discussão de paisagem em Milton Santos (1988), tem elementos importantes para o que aqui se 
propõe. "A sociedade só pode ser definida através do espaço, já que o espaço é o resultado da produção, uma decorrência de sua história - mais precisamente, da história dos processos produtivos impostos ao espaço pela sociedade" (SANTOS, 1988, p. 56). A paisagem é o resultado cumulativo do uso de determinadas técnicas, acumuladas entre a história do tempo passado e a história do tempo presente. Santos (1988), considera a ingerência do homem na construção da paisagem. É um movimento que olha para as transformações circunscritas dentro desses espaços. Este movimento é fruto de um processo produtivo imposto ao espaço. O que permite afirmar, ser a paisagem uma característica aproximativa com os dispositivos de enunciação da Indústria 4.0.

"No entanto, quanto mais o homem altera o espaço para criar uma paisagem repleta de artefatos e construções, tanto mais rígida se torna" (SANTOS, 1988, p. 67). O que temos, é um caminhar para uma rigidez a partir dos mecanismos de enunciação. Isto fica claro em dois enunciados. Primeiro, ao tomar o número 1, que trata da subjetividade, quanto o número 2, que evidencia o descrédito do sistema político como respostas às necessidades dos indivíduos. Enrijecem, porque enunciam uma ideia individualizante, como um processo geral. Alteram a coletividade em nome de um conjunto de individualidades. O que caracteriza uma análise aproximativa, pelo fato dele englobar a ideia de transformação da paisagem, evidenciando novas possíveis realidades. Os enunciados supracitados caminham nesta direção, de uma transformação da realidade dada para uma nova possível, que está construída a partir de novas tecnologias que causam, por si, novas estruturas. Sem, neste momento, julgar moralmente estas estruturas.

O que há em comum na correlação entre Santos (1988) e os enunciados do WEF, de 2019, é uma nova caracterização da história do tempo presente. Uma caracterização que altera a paisagem por meio da transformação. Num primeiro momento, de técnicas, para num segundo momento, das tecnologias, para sugerir novas atitudes frente ao mundo. Porém, todas estas ideias trazem implicações de ordem ecológica e moral sobre a vida.

\section{SEM PRINCIIPIOS ÉTICOS O NOVELO TORNA-SE UM NÓ "CEGO"}

Os dispositivos de enunciação, se comparados a primeira fase da Indústria 4.0 aos nossos dias, têm direcionado a discussão em questões de técnica, num primeiro momento, para tecnologias de novas atitudes no momento seguinte. Esta transformação do enunciado sugere pensar, também, questões de ordem comportamental. Para isso, recuperamos a ideia de ecologia em Boff (1993), onde 
ele apresenta uma discussão em vistas de uma ética integral. Para o autor, a ecologia é um estudo das relações e das condições que formam o ser humano, e que geram interpendência entre todos os seres vivos e o meio ambiente. Pensar a ecologia é pensar uma ciência das relações. A partir desta lógica, para pensar a Indústria 4.0, é preciso considerar também as relações que ela estabelece com o meio, e com tudo aquilo que forma o habitat que está inserida. Não há, neste texto, o objetivo de discutir o território ocupado por ela, mas pensá-la numa relação com meio, a partir de alguns apontamentos da ética, com vistas a uma ecologia integral.

Para Leonardo Boff (1993), todo o universo se relaciona, não há como separar fragmentos dele, e isolá-lo do todo. O autor compreende o estar com uma necessidade de cuidar. Tudo o que existe também coexiste. "A lesma tem a ver com a galáxia mais distante; a flor com a grande explosão de há 15 bilhões de anos; da descarga de dióxido de carbono de um ônibus velho com a nossa Via Láctea" (BOFF, 1993, n.p.). A partir de uma perspectiva holística pensaremos os dispositivos considerando também como estrategicamente, uma abordagem transdisciplinar.

Embora as ideias pareçam, em certo grau, desconexas, há uma ligação entre o que se propôs no objetivo desta investigação, com a temática da ética, a partir de uma leitura sistêmica. Para Boff (2009), as duas guerras mundiais, trouxeram crise para um tipo de razão unidirecional. Para o pensador, urge uma saída que ajuíze a humanidade em suas variáveis a partir de uma ética de compreensão holística. O alerta entende que, se a ética estiver reduzida a um simples caráter de utilidade para o funcionamento, ela pode ser também altamente destrutiva, ao ponto de pôr em xeque o futuro do planeta Terra. Com isso levará a escrever um ponto final a aventura humana. Mas qual a relação da abordagem de Boff, com as alterações dos dispositivos de enunciação da Indústria 4.0? Talvez, e só talvez, a saída para este imbróglio passe pela reflexão de uma abordagem de justiça e ética em John Rawls, como um alerta para pensar saídas diante de propostas que geram um desenvolvimento desigual.

Ao utilitarismo vastamente difundido de nossa cultura da eficiência e do lucro importa opor uma ética da justiça societária, como bem a elaborou John Rawls com o seu clássico Teoria da Justiça. Rawls diz que a centralidade da ética de ser ocupada pela liberdade e pela igualdade de oportunidades oferecidas a todos (BOFF, 2009, p. 78).

A preocupação de Boff $(1993 ;$ 2009) está centrada no princípio, que em cada nova fase de nossa história, se produz uma nova cosmologia. Se de fato o movimento da Revolução 4.0, e dentro dela a Indústria 4.0, se descrevem como uma nova fase da história da humanidade, caminhamos, pelo mesmo olhar, numa produção de uma nova cosmologia regida, por práticas vivenciais da tecnologia virtual. Pelo menos 
é o que está evidenciado nos dispositivos de enunciação. Como agora pensar esta cosmologia sem uma ética?

\begin{abstract}
Dado que as estruturas econômicas têm estes efeitos, e que na verdade, os devem ter, a sua escolha implica uma visão do bem humano e da concepção das instituições que permitem realiza-lo. Esta escolha deve, por ser feita com fundamentos políticos e morais, bem como econômicos (RAWLS, 1993, p. 210).
\end{abstract}

Diante de Rawls não existe a possibilidade de pensar uma nova cosmologia sem uma reflexão da ética. Mesmo diante de um discurso hegemônico em torno do capital, qualquer discussão só terá sentido, de um ponto de vista sistêmico, se houver uma escolha que tenha como princípio, uma visão do bem humano, amparado por mecanismos societários que visem a continuidade da aventura humana. Sem uma perspectiva sistêmica equitativa, recaímos numa razão utilitarista, que trouxe diversos percalços na história da humanidade. Evidência que serve de alerta diante de dispositivos, que não consideram os problemas decorrentes de ações que promovem o desenvolvimento desigual, que é o problema de fundo nos enunciados supracitados da Indústria 4.0. O que leva a outra reflexão, “o objetivo primário dos princípios de justiça social é uma estrutura básica da sociedade, ou seja, a articulação das principais instituições sociais num sistema único de cooperação" (RAWLS, 1993, p. 63).

O modelo de justiça e de ética em John Rawls visa o bem-estar social, como uma condição equitativa que visualize o justo e os injustos dentro de espaços institucionalizados, a pensar nossa organização societária. A justiça figura como virtude primeira das instituições. Pensar a Indústria 4.0, não se trata apenas de uma discussão de fomento político, para o desenvolvimento industrial tecnológico. Mas, pensar a Indústria 4.0, é pensar uma multiplicidade dentro do espaço que se está inserido. Não é uma questão de redução, com uma experiência com a vida. Entretanto é bom ter diante dos olhos, que ela é a fase da Revolução Industrial que desenhará novos contornos territoriais na vida existente. Moldará maneiras como nos organizamos societariamente o desenvolvimento. É também pensar um desenvolvimento, que em certa medida, produz uma desigualdade entre os habitantes da Mãe Terra, algo criticado por Leonardo Boff (1993; 2009). Um desenvolvimento, em certo grau, desigual. Consequência sempre presente em estratégias neoliberais. Se existe um campo que considera meios de produção com formação desigual, a independer das características, se faz necessário pensar questões que envolvam princípios que possam garantir uma certa segurança à vida humana. Esta segurança poderia, dito no campo teórico, seguir princípios de respeito à autonomia, a não-maleficência, a benevolência e a justiça. A julgar os campos de atuação que os dispositivos de enunciação da Indústria 4.0 penetram. A discussão dos limites é inerente ao tratar das técnicas que proporcionaram as 
primeiras enunciações da Indústria 4.0. A enunciação visa a manutenção da lógica produtiva, além da Indústria 4.0, pensa também a Revolução 4.0 como uma possibilidade totalitária, como Schwab (2016) lembra. Para este autor, a nova fase da revolução que está em curso alterará significativa a forma de vida em vários aspectos, daí a necessidade de se pensar em termos de uma ecologia integral com possível saída.

\section{CONSIDERAÇÕES FINAIS}

Gilles Deleuze propôs pensar determinados problemas a partir da figura de um novelo. Uma bola de fio, enrolada sobre si mesmo. A bola possui uma última camada, que é a externa. Depois de concluído o novelo, fica praticamente impossível acessar o início, que está na parte interna, sem antes desenrola-lo. O início dá corpo a bola, deixando para a última parte, o visível, aquilo que é externo ao novelo. $\mathrm{O}$ interno permanece invisível até o momento que o novelo seja remodelado. Um detalhe é importante, quando o interno se torna visível, o novelo já não é mais o mesmo, ele possui outro formato e outra lógica de montagem. É outra coisa, mas não deixa de ser um novelo. Tem outra aparência, mas mantém, uma mesma essência. O texto tem pretensão de ser novelo reflexivo, envolvido com uma última camada, ou uma outra aparência, para manter a comparação, que é o pensar a Filosofia da Tecnologia.

A Filosofia da Tecnologia é uma disciplina recente. Ela discute o homo faber a partir de uma abordagem heterogênea. O que permite dialogar com abordagens de ordem sistêmicas ou concepções holísticas da natureza, como foi a proposta de Leonardo Boff (1993). Avançando em outros pensadores, encontramos Ortega y Gasset (1963), onde alertou que o ser humano não se limita a adequar-se à natureza, mas ele adapta a natureza às necessidades e aos seus propósitos, transforma a natureza para si. Esta leitura permite afirmar que as mudanças enunciadas pela Indústria 4.0, são uma adaptação da natureza para propósitos humanos. Aqui entra a questão do que é Filosofia da Tecnologia. É pensar o caráter da técnica, do fazer que está presente na condição de ocupação da natureza, que o ser humano impõe, para uma reflexão da produção de algo que é artificial, como defende Cupani (2011). E todo este movimento possui implicações. A natureza é transformada por ações artificiais e adaptada diante daquilo que os dispositivos de enunciação elucidam como necessidade. Mas este pensar não poderia desvincular-se da ética por conta do desenvolvimento desigual que produz.

Para pensar o contexto de implicações, cabe lembrar que as mudanças que são alardeadas pelos dispositivos de enunciação da Indústria 4.0, enumeram as profissões do futuro, conforme Schwab (2016) e WEF (2018) desatacam. Pensar e usar 
o termo "profissões do futuro", implica em mudanças na forma como organizamos as ocupações profissionais e o mundo do trabalho e sugere que algumas ocupações terão espaço e outras serão descartadas. Então, há uma mudança de perspectiva que está no processo de enunciação. Cabe aqui a pergunta, quais são os mecanismos que garantirão, em certo grau, o cuidado com o outro dentro desta nova paisagem que se constitui? Ao buscar Rawls, o texto tentou entender os problemas de ordem social que envolvem o ser humano e seus habitats, que são as consequências de uma lógica do homo faber necessitam de princípios norteadores para garantir critérios com certa justiça dentro daquilo que se anuncia no WEF.

Há implicações inerentes na transformação enunciada pela Indústria 4.0, pois ela não é uma simples mudança. Nos séculos de vivência da Revolução Industrial, a humanidade, alterou completamente o modo de viver em função de um modo de produção. Primeiro pela mecanização dos processos, depois pela eletricidade, a introdução da informatização no pós-guerra e por fim, a virtualização de todos os espaços neste início de século. Todas as fases implicaram em mudanças significativas. Elas, de acordo com Boff (1993) interligam todos os entes envolvidos. Diante do que a Indústria 4.0 propõe, o artigo problematizou como uma abordagem mais fenomenológica. Se reduzirmos a discussão ao campo substancial ou apenas instrumental, corremos sério risco de ignorar implicações de caráter ético sobre a vida humana. Para dar conta de uma reflexão que considere o ser humano num espaço de preocupação com a Mãe Terra, urge olhar uma abordagem sistêmica que considere a vida como um valor essencial diante de todos os dispositivos que atentem contra ela, e também, aqueles dispositivos que sugerem uma mudança de técnica e de tecnologias comportamentais.

O texto inicia explorando uma condição construída a partir da subordinação ao trabalho. A história do tempo presente tem nos mostrado, através da automação dos meios de produção que há uma alteração significativa na forma como nos relacionamos com o trabalho e a institucionalização moral dele. Ele assume, por conta das características do desenvolvimento, um caráter de efemeridade na relação com o trabalhador. Vislumbramos uma prerrogativa que o problema não se construirá apenas na ausência de oferta de trabalho/emprego por uma nova lógica produtiva, mas isso terá como consequências a ausência de renda. A qualidade da oferta de trabalho/emprego se deteriorará na mesma velocidade que os processos de uberização crescerão. Um cenário que a curto prazo parece ser pessimista, urge discutir as transformações dadas a partir de uma perspectiva ética. Não é apenas a questão da Indústria 4.0 que vem ao debate, mas as perspectivas que estão contidas nos enunciados e toda uma lógica de transformação como fruto de uma proposta de desenvolvimento desigual. Parafraseando Ernesto Che Guevara, numa frase atribuída a ele, mas sem registro escrito, "desenvolver, porém, sem jamais perder a ternura". 


\section{PUBLICACÕES DO WORLD ECONOMIC FORUM SELECIONADAS}

BASON, Christian. BROEKAERT, Kris. Here are 4 tips for governing by design in the Fourth Industrial Revolution. 04.mar.2019. Disponível em: https://www.weforum. org/agenda/2019/03/four-tips-governing-by-design-fourth-industrial-revolutionpolicy-making/, acessado em 30.mar.2019.

GAWEL, Antonia. 4 key steps towards a circular economy. 14.fev.2019. Disponível em: https://www.weforum.org/agenda/2019/02/4-key-steps-towards-a-circulareconomy/, acessado em 30.mar.2019.

HEINONEM, Olli-Pekka. HYYTIÄLÄ, Hernanini. Don't compare data to oil digitization needs a new mindset. 22.mar.2019. Disponível em: https://www.weforum. org/agenda/2019/03/dont-compare-data-to-oil-digitization-needs-a-new-mindset/, acessado em 30.mar.2019.

LEVIN, Mariah. Meet the 2019 Class of Young Global Leaders. 12.mar.2019. Disponível em: https:/www.weforum.org/agenda/2019/03/meet-the-2019-class-of-youngglobal-leaders/, acessado em 30.mar.2019.

WEF - World Economic Forum. Civil Society in the Fourth Industrial Revolution: Preparation and response. 23.jan.2019. Disponível em: https://www.weforum.org/ whitepapers/civil-society-in-the-fourth-industrial-revolution-preparation-andresponse, acessado em 30.mar.2019.

\section{REFERÊNCIAS}

BAUMAN, Zygmunt. Capitalismo parasitário. Rio de Janeiro: Jorge Zahar Ed., 2010.

BENVENIESTE, Emile. Problemas de linguistica general. 7 Ed. México DF: Siglo Veintiuno, 1978.

BOFF, Leonardo. Ecologia, mundialização e espiritualização. São Paulo: Editora Ática, 1993.

. Ética da vida: a nova centralidade. Rio de Janeiro: Record, 2009.

BRYNJOLFSSON, Erik. MCAFEE, Andrew. A segunda era das máquinas. Rio de Janeiro: Elsevier/Altabooks, 2019. 
CASE, Steve. Terceira onda da internet: a reinvenção dos negócios na era digital. São Paulo: HSM, 2017.

CUPANI, Alberto. Filosofia da tecnologia: um convite. Florianópolis: Editora da UFSC, 2011.

DELEUZE, Gilles. ¿Que és un dispositivo? In: Michel Foucault, filósofo. Barcelona: Gedisa, 1990, pág. 155-161.

DELEUZE, Gilles. GUATTARI, Félix. O que é a filosofia? 3 Ed. São Paulo: Editora 34, 2013.

HEIDEGGER, Martin. The question concerning technology? New York: Harper, 1977.

ORTEGA Y GASSET, José. Meditação da técnica. Rio de Janeiro: Livro Ibero-Americano, 1963.

PAUL, Patrick. Pensamento complexoeinterdisciplinaridade: abertura para mudança de paradigma? In: PHILLLIPI JUNIOR, A. SILVA NETO, A. Interdisciplinaridade em ciência, tecnologia e inovação. Baueri: Manoele, 2011, p. 229-258.

RAWLS, John. Uma teoria da Justiça. Trad. de Carlos Pinto Correia. Lisboa: Editorial Presença, 1993

SANTOS, Milton. Espaço e Método. São Paulo: Nobel, 1988.

SCHWAB, Klaus. A quarta revolução industrial. São Paulo: Edipro, 2016.

WEF - World Economic Forum. The Future of Jobs Report 2018. Genova: 2018. 